\title{
A PÓS-VERDADE COMO ACONTECIMENTO DISCURSIVO
}

\author{
Post-truth as a Discursive Event $\mid$ Posverdad cómo acontecimiento discursivo
}

\author{
Silvânia Siebert* \\ Israel Vieira Pereira** \\ Universidade do Sul de Santa Catarina, \\ Programa de Pós-Graduação em Ciências da Linguagem, Tubarão, SC, Brasil
}

Acreditamos que o contexto de pandemia trouxe muitos debates sobre a importância do fazer científico, o perigo de notícias falsas e informações desencontradas e outros desafios. Rediscutir o que é pós-verdade e analisar seus efeitos pode suscitar reflexões pertinentes no atual contexto histórico e cultural. Portanto, buscamos traçar um percurso de análise do funcionamento discursivo do que se tem chamado de pós-verdade para investigar se o termo se constitui como acontecimento discursivo e como funciona na contemporaneidade para justificar movimentos de negacionismo e de populismo, por exemplo.

Uma marca discursiva interessante sobre a pós-verdade é sua publicação no dicionário Oxford. Pós-verdade, nos termos do dicionário, é um adjetivo definido da seguinte forma: Relating to or denoting circumstances in which objective facts are less influential in shaping public opinion than appeals to emotion and personal belief ${ }^{1}$. Ganha mais notoriedade a partir da divulgação de sua escolha como "a palavra do ano" pelo Dicionário Oxford, em 2016, tendo em vista seu uso cada vez mais regular em publicações de grande circulação, como a revista The Economist (2016) e o jornal The Independent (NORMAN, 2016), embora a pós-verdade tenha como seu primeiro registro a publicação de um artigo do cineasta Steve Tesich para a revista The Nation em 1992. $\mathrm{Na}$ época o autor definia pós-verdade como uma espécie de inclinação social em que a verdade não era tão importante quanto o que se imaginava verdadeiro. A publicação no Dicionário Oxford, repercutida em veículos de comunicação de todo o mundo, nos faz

* Doutora em Linguística Aplicada pela Universidade Estadual de Campinas. Docente do Programa de Pósgraduação em Ciências da Linguagem da Universidade do Sul de Santa Catarina. Editora de Linguagem em (Dis)curso. ORCID: https://orcid.org/0000-0002-7852-0968. E-mail: silvania@ cinemaistv.com.br.

** Doutorando no Programa de Pós-Graduação em Ciências da Linguagem da UNISUL. Agradecemos à CAPES/FAPESC pelo fomento à pesquisa de Doutorado, sem a qual a colaboração para a escrita deste editorial seria impossível. ORCID: https://orcid.org/0000-0001-5295-2503. E-mail: israelvpereira@hotmail.com.

${ }^{1}$ Em tradução livre: "Relacionado a ou denotando circunstâncias em que fatos objetivos são menos influentes na formação da opinião pública do que apelos à emoção e a crenças pessoais”. O verbete pode ser acessado no endereço: https://en.oxforddictionaries.com/definition/us/post-truth. 
pensar o "fenômeno" como um acontecimento discursivo a partir da análise que Pêcheux fez em seu livro: $O$ discurso: estrutura ou acontecimento. No texto, Pêcheux analisa a eleição de François Mitterand, na França, em 10 de maio de 1981. Para o autor, o enunciado "On a gagné (ganhamos)" marcou um fato novo, um evento político e midiático da eleição do presidente francês. Seria um acontecimento de ordem global da máquina televisiva e um "acontecimento jornalístico e da mass-media [sic] que remete a um conteúdo sócio-político ao mesmo tempo perfeitamente transparente (o veredito das cifras, a evidência das tabelas) e profundamente opaco." (PÊCHEUX, 2015, p.19-20). A crítica de Pêcheux se dirigia à ciência régia, ao positivismo, que contribuiria para a compreensão da transparência dos sentidos, dos números e da competição, e levou o autor a dizer sobre a necessidade de "se pôr na escuta das circulações cotidianas" (PÊCHEUX, 2015, p.48). Para o autor, a análise do ordinário aliada às práticas de leitura seria uma forma de trabalho que "engaja concretamente maneiras de trabalhar sobre as materialidades discursivas, implicadas em rituais ideológicos, nos discursos filosóficos, em enunciados políticos, nas formas culturais e estéticas, através de suas relações com o cotidiano, com o ordinário do sentido" (PÊCHEUX, 2015, p. 49). Isso nos permitiria, por exemplo, questionar as teorias positivistas e as filosofias da consciência.

Para promover esta reflexão, nas próximas seções, buscamos estabelecer relações entre os estudos linguísticos/discursivos (PÊCHEUX, 2015; ORLANDI, 2012a, 2012b), os estudos da mídia e jornalismo (CHARAUDEAU, 2013) e os da filosofia (ARENDT, 2011; FOUCAULT, 2013). Este entrecruzamento de saberes constitui-se necessário para a aproximação entre os diferentes modos de pensar o conceito de verdade como condição de existência e que estão envolvidas na regulação e funcionamento da interpretação e da relação humana com o real, e consequentemente ligadas à cadeia de sentidos do termo pós-verdade.

\section{PÓS-VERDADE E ACONTECIMENTO}

Propomos pensar o termo pós-verdade a partir de sua divulgação como a palavra do ano do Dicionário Oxford, como um termo que, nos moldes de On a gagné, enuncia um novo acontecimento. Em seu verbete, o dicionário Oxford (MIDGLEY, 2016) descreve Pós-Verdade como um adjetivo relacionado a circunstâncias em que os fatos influenciam menos a opinião pública do que apelos à emoção ou às crenças pessoais. Nos jornais de grande circulação, sua publicação passou a ser recorrente em notícias para significar eventos ligados ao debate político. Os fatos, a comprovação de dados e estatísticas teriam pouca influência na formulação do sentido e na interpretação dos leitores e de eleitores.

Sobre as condições de veiculação do termo pós-verdade vemos que, em 2016, passou a ser mais frequente durante as campanhas presidenciais americanas - na eleição de Donald Trump à Presidência da República - e nos momentos derradeiros do referendo que decide pela separação do Reino Unido da União Europeia (Brexit). Esse uso recorrente faz sentido para a mídia, principalmente para o jornalismo, ao nomear e significar o momento vivido. À época, os institutos de pesquisa usados pelos meios de comunicação como fontes de credibilidade para as projeções futuras davam como certa a 
vitória de Hillary Clinton e a permanência do Reino Unido junto à União Europeia (UE). Nestes dois casos, os prognósticos dos meios de comunicação de massa ligados aos conglomerados de mídia projetaram expectativas que não se concretizaram. Uma das razões poderia estar na internet? Em novas formas de comunicação? Em novas fontes de informação? Neste cenário, os leitores de notícias tinham, além dos meios convencionais, novos canais de conteúdo que, em muitos casos, contestam os ditos dos mass media e o prognóstico dos meios de comunicação de massa, colocando em xeque o conceito de verdade por eles propagado como princípio de funcionamento. As figuras 1 e 2 abaixo ilustram isso:

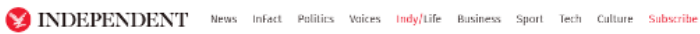

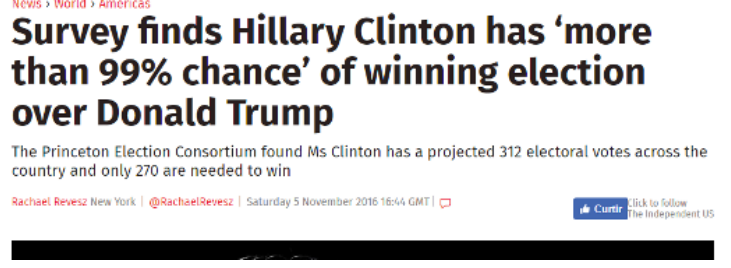

Figura 1 - Manchete do The Independent: "Pesquisa aponta que Hillary Clinton tem 'mais de 99\% de chances' de vencer Donald Trump nas eleições" (tradução nossa)

Fonte: Captura de tela. Disponível em: <http://www.independent.co.uk/news/world/americas/sam-wang-princetonelection-consortium-poll-hillary-clinton-donald-trump-victory-a7399671.html>. Acesso em 24 jun. 2020.



Figura 2 - Manchete do Breitbart: "Análise: Donald Tump venceria eleições hoje de acordo com pesquisa recente" (tradução nossa)

Fonte: Captura de tela. Disponível em: <http://www.breitbart.com/big-government/2016/09/26/analysis-donaldtrump-would-win-election-today-based-current-polling/>. Acesso em 24 jun. 2020.

O tradicional jornal britânico The Independent, por exemplo, seguindo a mesma linha de canais de mídia tradicionais como CNN, The New York Times e Washington Post, noticiava que as chances de vitória de Clinton eram bastante grandes. Em algumas previsões, as chances de vitória chegavam aos 99\%. Por outro lado, veículos menos 
tradicionais, tal como o portal de notícias Breitbart, com linha editorial voltada à direita, apontavam que as chances de vitória de Trump eram maiores, ainda que não tão grandes quanto veículos tradicionais supunham.

Ao analisarmos tais enunciados, o uso do termo pós-verdade também passa a significar um momento histórico com expressivo aumento na velocidade da comunicação que, entre outras coisas, multiplica a quantidade de informações com as quais precisamos lidar diariamente. $\mathrm{O}$ termo passa a ser usado para nomear esse viver imerso em novas condições de produção de sentido. Nessa perspectiva, acreditar na informação ou classificá-la como mentirosa de imediato representa um reforço de posicionamento possibilitado pelo caráter ideológico do processo de interpretação. Segundo Orlandi (2012a, p. 66), a ideologia "não se liga à falta, mas ao excesso. A ideologia representa a saturação, o efeito de completude que, por sua vez, produz o efeito de 'evidência', sustentando-se sobre o já dito, os sentidos institucionalizados, admitidos por todos como "naturais"”. Na pós-verdade, o excesso de informações gera um número maior de "jáditos" sobre os quais diversos matizes ideológicos podem se firmar. A informação (re)significa o real, materializando-se discursivamente enquanto acontecimento. Ideologicamente, os veículos tradicionais reivindicavam a vitória de Hillary por tradição política, pelo eleitorado que traria de Barack Obama (da qual foi Secretária de Estado) e, acima de tudo, por ser apresentada como contraposição a Donald Trump. O tradicional jornal The Atlantic, por exemplo, endossou a candidatura de Hillary por ser rival de Trump, mas não o faria se o candidato republicano fosse qualquer outro. Essa foi a terceira vez na história que o jornal endossou uma candidatura à presidência - as duas outras foram de Abraham Lincoln, em 1860, e Lyndon Johnson, em 1964. Conforme o editorial da publicação:

\begin{abstract}
Em seu primeiro editorial, The Atlantic prometeu que seria “o órgão sem partidos ou vieses", e nosso interesse aqui não é apoiar a agenda do Partido Democrata, nem danificar a do Partido Republicano. Se Hillary Clinton estivesse concorrendo contra Mitt Romney, John McCain, George W. Bush ou qualquer outro dos principais candidatos que Trump aniquilou nas primárias Republicanas, sequer teríamos contemplado tal tipo de endossamento. ${ }^{2}$ (AGAINST DONALD, 2016, destaque nosso)
\end{abstract}

Trump, por sua vez, era descrito como o candidato de tendências extremistas, pouco confiável, com discurso marcantemente populista e rejeitado até mesmo por parte da intelectualidade conservadora americana. Em editorial, o jornal conservador The National Review (2016), por exemplo, destaca que as opiniões de Trump, anteriormente membro do Partido Democrata, são extremamente voláteis, algo que não coincidiria com qualquer filosofia política conservadora.

\footnotetext{
${ }^{2}$ In its founding statement, The Atlantic promised that it would be "the organ of no party or clique," and our interest here is not to advance the prospects of the Democratic Party, nor to damage those of the Republican Party. If Hillary Clinton were facing Mitt Romney, or John McCain, or George W. Bush, or, for that matter, any of the leading candidates Trump vanquished in the Republican primaries, we would not have contemplated making this endorsement.
} 
Em resumo, a mídia tradicional se opunha a Trump e buscava consolidar o resultado desejado: a vitória de Hillary Clinton. Entretanto, o acontecimento histórico rompeu com as expectativas dessa mídia, trazendo mais instabilidade à legitimidade dos meios de comunicação consolidados. Para entender as origens de tal instabilidade, é preciso reconhecer os mecanismos de produção e interpretação de acontecimentos. É por essa discussão que podemos abordar a opacidade da língua e as condições de produção de convicções.

Ao analisar o enunciado On a gagné, Michel Pêcheux coloca em debate a produção do acontecimento discursivo. Para que um acontecimento tenha relevância na sociedade, é preciso que ele circule. On a gagné, por sua vez, eram palavras comumente usadas por torcedores franceses em partidas de futebol. Tais palavras ganharam contorno político após a vitória de Mitterand, quando os telejornais exibiam as ruas de Paris lotadas de cidadãos gritando On a gagné em comemoração ao resultado das eleições. É por isso que, assim como tantos outros, este enunciado:

\footnotetext{
[...] é profundamente opaco: sua materialidade léxico-sintática (um pronome "indefinido" em posição de sujeito, a marca temporal-aspectual de realizado, o lexema verbal "gagner" ["ganhar"]. A ausência de complementos) imerge esse enunciado em uma rede de relações associativas implícitas - paráfrases, implicações, comentários, alusões, etc. - isto é, em uma série heterogênea de enunciados, funcionando sob diferentes registros discursivos, e com uma estabilidade lógica variável. (PÊCHEUX, 2015, p. 23)
}

Sendo assim, os acontecimentos não têm um sentido em si mesmos: eles remetem a uma série de outros elementos subjetivos que conduzem a significação, que por sua vez só pode existir enquanto materialidade perceptível, como notícias, comentários ou previsões. Pelo viés discursivo, entendemos que significamos o mundo pela linguagem e agimos sobre ele simbolicamente, atravessados pelo inconsciente, o interdiscurso, a história, enfim, pelo conjunto de circunstâncias sociais, históricas e simbólicas que chamamos de condições de produção do sentido. Condições estas que legitimam posturas ideológicas de interpretação, servindo de fio condutor entre dizeres do passado e enunciados do presente. Relacionando ao termo pós-verdade, identificamos como condição de produção ampla o seu primeiro uso.

O termo pós-verdade data de 1992, cunhado pelo novelista Steve Tesich, serviria para definir o comportamento dos americanos perante o caso Watergate, nomeando uma série de abusos de poder relacionados ao governo do então presidente Richard Nixon. $\mathrm{O}$ autor sugere que os cidadãos americanos passem a reagir de forma diferente à verdade depois do caso, associando-a a sentimentos negativos e problemas. Por sua vez, essa relação negativa com a verdade faria com que as pessoas tendessem a se proteger contra ela e suprimir seus efeitos, dando força a políticas totalitárias.

A definição de pós-verdade nasce atrelada ao gesto político, significado uma sociedade que se importa mais com seu bem-estar diante das informações do que com a qualidade delas ou sua ligação com o real. Guiado pela ideologia, o sujeito é inclinado a ser seletivo no que toca a suas crenças, admitindo como verdadeiras as informações que conferirem reforço discursivo à sua posição ideológico-histórica. 
Em um primeiro momento, poderíamos argumentar que a pós-verdade ganha força sempre que há certa urgência em linearizar, homogeneizar e dar sentido às inúmeras informações e acontecimentos com os quais convivemos diariamente. Entendemos que informações podem ser inventadas ou manipuladas pelos veículos de mídia, por exemplo, desde que satisfaçam certas peculiaridades de um dado conjunto ideológico de crenças. Adotar a realidade como referência - uma referência inconstante, que sob a lógica discursiva ganha múltiplas leituras possíveis - se torna menos importante do que criar uma realidade particular, em que a interpretação se lineariza porque o acontecimento não existe fora de um contingente ideológico qualquer, sem espaço para a dúvida.

Na pós-verdade, mais do que interpretar e significar o acontecimento, cria-se uma versão que o sujeito tende a interpretar como verdadeira ou não, independente de investigações científicas quaisquer. Tal gesto interpretativo é possível devido à fluidez da informação, por sua instabilidade, por retratar um mundo tão farto de acontecimentos, tão amplo em dimensões planetárias e contraditório nos dizeres. Em função dessas grandezas, buscamos estabilidade para os sentidos. Por isso, aderimos ao que nos convém como verdade através da ideologia, que atua como dispositivo ordenador de informação, rendendo-lhe sentidos. As consequências do reforço de posição por meio de enunciados legitimados apenas por aspectos ideológicos puderam ser sentidas em setembro de 2016, no auge das campanhas dos candidatos à Presidência dos Estados Unidos Donald Trump e Hillary Clinton. À época, a revista The Economist publicou um artigo chamado Art of the Lie, voltado à reflexão sobre a política da pós-verdade. No artigo, a revista definia política de pós-verdade como estratégia em que sentimentos valem mais que a razão no debate político: "Nesse tipo de campanha política, o que importa não são os fatos, mas sim os sentimentos. A descrença dos seus oponentes valida a mentalidade de nós-contraeles do qual candidatos fora da política tradicional se aproveitam." 3 (ART OF THE, 2016).

A publicação enfatiza aqui o embate entre diferentes posições em luta por domínio político e moral. A pós-verdade não só validaria informações inverossímeis como também serviria para distinguir os sujeitos no espectro político: acreditar em uma informação em detrimento de outras firmaria seu apoio a um ou outro candidato. Em um regime de pós-verdade, ou se acredita totalmente em certos dizeres, ou se faz parte da oposição. Não há meio-termo possível. Como exemplos, a publicação traz declarações de Trump como "A certidão de nascimento de Barack Obama foi falsificada" e que o pai de um rival político "seria amigo de Lee Harvey Oswald, o assassino de JFK". Tais enunciados são interpretados como acontecimentos pela memória implicada e por sua circulação persistente nos mais diversos veículos de mídia contemporâneos, tais como redes sociais, blogs e os próprios jornais. Ao comentarem tais enunciados, transformamnos em acontecimentos discursivos nos quais os sujeitos ancoram seus dizeres e posturas ideológicas.

\footnotetext{
${ }^{3}$ Feelings, not facts, are what matter in this sort of campaigning. Their opponents' disbelief validates the us-versus-them mindset that outsider candidates thrive on.
} 
Segundo Keyes (2004) - um dos primeiros autores a escrever um livro inteiro dedicado ao estudo da pós-verdade -, o termo permite dissimular ações sem deixar de manter uma postura aparentemente ética. Se ética é forma de agir sobre o mundo, só se age sobre o mundo inserido numa posição. Em uma sociedade de pós-verdade, busca-se legitimar certas posições através da construção de verdades não legitimadas. Materializada linguisticamente, a pós-verdade provoca "efeitos de verdade" na forma de enunciados que podem ser resumidos em poucas palavras e servir de bandeiras de ação política, manchetes, bordões e dizeres de protesto. O foco é a ressonância do sentido: aqueles que repetem mais vezes a informação através dos mais variados meios, de livros a postagens na internet, de piadas a artigos sérios conquistam seu espaço de ação política e o subsequente silenciamento de elementos de verdades fatuais. Tal ressonância atua como contraponto ao aparente monopólio da verdade detido pelos veículos tradicionais de mídia, abalando, assim, a própria noção de confiabilidade dos sujeitos.

Charaudeau (2013), ao pensar o discurso da mídia, propõe que há uma contraposição fundamental entre valor de verdade e efeito de verdade. $O$ valor de verdade estaria relacionado aos saberes legitimados pelas ciências e por aparatos institucionais. Algo com valor de verdade só tem tal valor em função dos aparatos institucionais que lhe dão suporte e legitimidade. $\mathrm{O}$ valor de verdade é um dos frutos do desejo por um mundo semanticamente estável, uma busca constante pela catalogação e racionalização de uma verdade fatual. Contrapondo-se ao valor de verdade de nível institucional, Charaudeau (2013, p. 49) apresenta o efeito de verdade, que surge "da subjetividade do sujeito em sua relação com o mundo, criando uma adesão ao que pode ser julgado verdadeiro pelo fato de que é compartilhável com outras pessoas, e se inscreve nas normas de reconhecimento de mundo".

O efeito de verdade funciona também para o sujeito como forma de estabilizar o dizer. Esse efeito é possível porque, em princípio, realidade e língua se relacionam apenas em uma dimensão imaginária da discursividade fundadora de sentidos e sujeitos: "a dimensão imaginária de um discurso é sua capacidade para a remissão de forma direta à realidade. Daí seu efeito de evidência, sua ilusão referencial" (ORLANDI, 2012a, p. 32). É no nível discursivo - considerando sempre as relações com as dimensões sociais e históricas dos processos de significação - que os sujeitos constroem seus sistemas de crenças e, consequentemente, suas concepções de verdade. Pêcheux (2015, p. 29) assumia: "Não descobrimos [...] o real: a gente se depara com ele, dá de encontro com ele, o encontra."

O debate em torno da conceituação de verdade e como ela nos afeta é antigo na filosofia. Sócrates, como narrado por Platão no diálogo Fedro, já operava com a distinção entre verdade e convencimento para tratar do embate entre filósofos e sofistas. Segundo Sócrates, nas palavras de Platão, foram Górgias e Tísias, fundadores da Escola siciliana de retórica, que compreenderam que "o que é provável é digno de maior estima do que o que é verdadeiro, que transmite aparência de grandeza às coisas pequenas e aparência de pequenez às grandes graças ao poder de suas palavras" (PLATÃO, 2012, p. 98). A percepção do que seria verdadeiro estaria relegado ao poder do convencimento, e não de um trabalho filosófico ordenado de forma a alcançar a verdade exterior às palavras. 
Em contrapartida, a visão aristotélica pressupõe que a verdade conseguiria ser mais forte que a opinião por ser exterior à língua e às estratégias retóricas. Seguindo essa lógica, poderíamos chegar a uma dicotomia conceitual entre Verdade de Opinião e Verdade Fatual. A primeira "se baseia em sistemas de crença e procura ser compartilhada pela maioria, sendo que esse compartilhamento estabelece um consenso que seria garantidor de seu valor" (CHARAUDEAU, 2013, p. 267), enquanto que a última é "estabelecida por testemunhas e depende de comprovação; existe apenas na medida em que se fala sobre ela, mesmo quando ocorre no domínio da intimidade" (ARENDT, 2011, p. 295). Note-se, porém, que a Verdade Fatual exige o uso da língua para se espalhar e se firmar, uma vez que é necessário se falar sobre ela. A língua, por sua vez, é atravessada pelas subjetividades, que se formam para além da intervenção dos aparatos institucionais de verificação e difusão daquilo que se propõe verdades objetivas. O uso do termo pósverdade significa um momento histórico que reforça aquilo que Foucault (2013, p.11) defendia ao argumentar que existem dois tipos de história sobre a verdade: uma interna, formal, e outra exterior, ligada ao fazer da história.

Relacionando o dizer de Foucault com o termo pós-verdade, este último tem seu valor de verdade regulado pelo funcionamento do sentido, da noção de que os meios de comunicação são imparciais e retratam a verdade, e também pelo momento vivido, este momento histórico em que sentidos contrários colocam em xeque a versão de verdade, uma vez que outros enunciadores "desdizem" o que os meios de comunicação de massa afirmam ser verdadeiro. $\mathrm{O}$ discurso jornalístico, um dos discursos que dá sustentação aos discursos da mídia, é um dos principais discursos que justifica sua formulação a partir do conceito de verdade.

Em Análise do Discurso, dizemos que certos sentidos ganham maior legitimidade e notoriedade conforme ressoam na língua, mas sem deixar de observar que é a partir da ressonância que podemos encontrar os deslizamentos de sentido, os novos dizeres. Quando há um deslizamento nessa regularidade, é preciso significá-la e situar suas condições de produção. É das mídias tradicionais que o termo irrompe, significando essa quebra na pretensa estabilidade que elas conferiam à verdade.

Como vimos até aqui, viver no real pressupõe interpretar e ressignificar esse real pela língua. Não ignoramos acontecimentos da realidade sensível - as verdades fatuais defendidas por Arendt -, e tampouco vivemos completamente presos a uma segunda realidade exclusivamente simbólica. Vivemos num constante estado de conflito entre o mundo real e o discursivo, entre as verdades do mundo e as da língua.

\section{A VERDADE E A PÓS-VERDADE NA MÍDIA E NO JORNALISMO}

A pós-verdade se intensifica com as mídias digitais justamente pela proporção e velocidade com que a ressonância de sentidos pode acontecer. Por isso os veículos tradicionais de mídia têm dificuldade de manter certo grau de confiabilidade: eles não detêm mais o monopólio da "verdade". Com a internet, e em especial com as redes sociais e a aparente proximidade que ela traz com formadores de opinião dos mais diversos, tal monopólio se fragmenta. Isso gera resultados positivos - o maior espaço para o debate 
entre posições conflitantes, por exemplo - e negativos - a maior capacidade de produzir e difundir boatos. A pós-verdade, como postulou Tesich (1992), é um sentimento coletivo que não só permite que informações de caráter duvidoso circulem, como também as incentiva, desde que tragam alguma espécie de alívio moral e ético aos sujeitos. No seu estado de descrença, o sujeito precisa se agarrar a algo em que possa acreditar cegamente.

Trump, por exemplo, é conhecido por seu frequente uso do Twitter, rede social de grande alcance que preza por postagens curtas de até 280 caracteres. Nela, já acusou Barack Obama de ser um conspirador muçulmano e alegou que vacinas são a causa de autismo (YUHAS, 2016). São informações que reforçam determinadas posições subjetivas e que representam um problema para o jornalismo tradicional: a mídia se vê obrigada a tratar de Trump e suas alegações com o fim de refutá-lo, mas acaba dando maior exposição a ele e a suas ideias, ressoando-as. Quanto ao Brexit, a alegação que mais pesou, de acordo com a jornalista Anne Applebaum (2017), do Washington Post, foi a de que o Reino Unido economizaria até 350 milhões de libras por semana com a saída da União Europeia. O dado desconsideraria os aportes financeiros da UE ao Reino Unido e outras variações estatísticas.

$\mathrm{Na}$ era da pós-verdade, pouco importa se o acontecimento foi verificado e refutado: a verdade, mais do que nunca, está nas impressões subjetivas que uma dada informação causa. Segundo Orlandi (2016):

\footnotetext{
[Revista Galileu traz:] Trump se esquivou de acusações de sonegação de impostos ao rir da própria tragédia em vez de apelar para as retratações sérias costumeiras na vida política. "O que ele falou foi quase um 'Olha, eu consegui. Vocês também não gostariam de conseguir enganar?' Claro, ninguém gosta de pagar imposto. E ele pode falar porque é em tom de brincadeira, e não de coisa séria.
}

Seguindo a análise feita por Orlandi, o discurso de Trump faz uso da ironia, rompe com a estabilidade da verdade e, em nosso entendimento, adere aos traços da pós-verdade. A ironia se constitui como marca discursiva da pós-verdade porque não se assenta nas bases de um sentido estável, saturando-o de contradições. A pós-verdade, ironicamente, ri de si própria, ao encenar a ruptura da verdade. Orlandi apresenta marcas textuais próprias da ironia como: menção, antítese, perífrase, interrogação, e no nível da gramática a confrontação de elementos de estilos diferentes, jogo entre som/sentido, repetição, mudança de registro e tom (ORLANDI, 2012b, p. 38). Para ilustrar, retomando exemplo anterior, temos o enunciado "Vacinas causam autismo". Nele, identificamos uma marca irônica de antítese. Vacina é uma palavra que traz como significado, no dicionário Dicio on-line: "substância que, contendo certos agentes patológicos, mortos ou atenuados, é introduzida no organismo para provocar a formação de anticorpos, desenvolvendo imunidade às doenças por eles causadas", e está ligada a sentidos do senso comum como saúde, bem-estar, cura; a palavra autismo, por outro lado, no mesmo dicionário, é descrita como

Transtorno global do desenvolvimento, caracterizado pela incapacidade de interação social, pela dificuldade na comunicação verbal, ou no uso da linguagem, e pela concentração excessiva em pensamentos e sentimentos pessoais em detrimento do mundo exterior. (DICIO, 2019) 
Em nossa análise, Trump, ao relacionar vacina e autismo, produz uma antítese que, por sua vez, também produz o efeito de interrogação, uma vez que, ao romper essa cadeia de sentidos, algumas perguntas ficam subentendidas para quem interpreta o enunciado. É como se Trump perguntasse: "Será que vacina pode causar autismo? O governo sabe dessa suposta relação entre vacinas e autismo? Por que ninguém além de mim fala sobre esse assunto?". Ele demarca uma posição de questionador e funda sentidos nos quais sujeitos podem firmar novos enunciados e novas crenças, colocando-o como arauto de uma verdade que desafia a ciência, o Estado e outras fontes de informação tidas por oficiais, críveis e respeitáveis. A pós-verdade institui-se como um acontecimento que suporta esses novos dizeres irônicos, rompendo com a dualidade mentira-verdade.

\section{CONCLUSÃO}

A pós-verdade se materializa na forma de memes, piadas, manchetes, livros, boatos, enfim, uma sucessão de enunciados rápidos e constantes que ressoam certos sentidos, fundamentam determinadas posições e se contrapõem ao senso comum. Simultaneamente, a pós-verdade parece anteceder o enunciado, estando na ordem do ideológico.

A pós-verdade se constitui em acontecimento discursivo ao ser escolhida a palavra do ano pelo dicionário Oxford. Funciona em tempos de grande insatisfação e descrença política - nos Estados Unidos, por exemplo, ela surge depois do caso Watergate, tornando-se um termo recorrente de análise décadas depois, durante as eleições norteamericanas de 2016 e do Brexit, também em 2016. Ambos os resultados dos acontecimentos políticos foram inusitados do ponto de vista da grande mídia, dos institutos de pesquisa e da percepção do senso comum.

A pós-verdade se fortalece com as mídias digitais, uma vez que os veículos tradicionais de informação não detêm mais o monopólio da "verdade". Com a internet, as redes sociais, os formadores de opinião são os mais diversos, fragmentando assim o controle sobre circulação da informação, em especial da notícia, gerando assim mais debates e maior capacidade de produzir e difundir novas versões sobre os acontecimentos. Um dos aspectos marcantes da pós-verdade é o traço de ironia, no sentido de que ela, como apontado por Orlandi (2012b), desestabiliza sentidos antes considerados estáveis e previsíveis, além de atacar a credibilidade de instituições já consagradas, como a própria academia. A consequência disso é a popularização do negacionismo, das falácias e de teorias da conspiração como plataformas viáveis — ainda que não o sejam — de debate. Contra esse fenômeno, faz-se necessário responder com uma leitura crítica e científica. 
AGAINST DONALD. The Atlantic, Nov. 2016. Disponível em:

https://www.theatlantic.com/magazine/archive/2016/11/the-case-for-hillary-clinton-and-against-donaldtrump/501161/. Acesso em: 5 set. 2017.

AGAINST TRUMP. National Review, 21 jan. 2016. Disponível em:

http://www.nationalreview.com/article/430137/donald-trump-conservative-movement-menace. Acesso em: 5 set. 2017.

ARENDT, H. Entre o passado e o futuro. 7. ed. Trad. de Mauro W. Barbosa. São Paulo: Perspectiva, 2011.

APPLEBAUM, A. All the worst lies about Brexit are about to be revealed. Washington Post, 7 set. 2017. Disponível em: https://www.washingtonpost.com/opinions/global-opinions/all-the-worst-lies-aboutbrexit-are-about-to-be-revealed/2017/09/08/4bf9d43a-9410-11e7-8754d478688d23b4_story.html?utm_term=.5855a5679100 Acesso em: 16 set. 2018.

ART OF THE., Art of the lie. The Economist, 10 set. 2016. Disponível em: http://www.economist.com/news/leaders/21706525-politicians-have-always-lied-does-it-matter-if-theyleave-truth-behind-entirely-art Acesso em: 26 jan. 2017.

CHARAUDEAU, P. Discurso das mídias. 2. ed. Trad. de Angela M. S. Corrêa. São Paulo: Contexto, 2013.

DICIO, dicionário on-line. Disponível em: https://www.dicio.com.br/. Acesso em: 16 set. 2018.

FOUCAULT, M. A verdade e as formas jurídicas. 4. ed. Trad. de Eduardo Jardim e Roberto Machado. Rio de Janeiro: Nau, 2013.

KEYES, R. The post truth era: dishonesty and deception in contemporary life. Londres: Macmillan, 2004.

MIDGLEY, N. Word of the year 2016 is... Oxford, 8 nov. 2016. Disponível em: https://en.oxforddictionaries.com/word-of-the-year/word-of-the-year-2016. Acesso em: 26 jan. 2017.

NORMAN, M. Whoever wins the US presidential election, we've entered a post-truth world - there's no going back now. The Independent, 8 nov. 2016. Disponível em: http://www.independent.co.uk/voices/uselection-2016-donald-trump-hillary-clinton-who-wins-post-truth-world-no-going-back-a7404826.html. Acesso em: 26 jan. 2017.

ORLANDI, E. P. Interpretação: Autoria, leitura e efeitos do trabalho simbólico. 6. ed. São Paulo: Pontes, 2012a.

ORLANDI, E. P. Destruição e construção do sentido: um estudo da ironia. Web Revista Discursividade, Campo Grande, Edição n. 9, $1^{\circ}$ sem. 2012b.

ORLANDI, E. P. Pedimos a uma linguista para analisar o discurso de Donald Trump. [Entrevista concedida a Bruno Vaiano]. Galileu, 10 nov. 2016. Disponível em:

https://revistagalileu.globo.com/Sociedade/noticia/2016/11/pedimos-uma-linguista-para-analisar-odiscurso-de-donald-trump.html. Acesso em: 11 set. 2017.

PÊCHEUX, M. O discurso: estrutura ou acontecimento. 7. ed. Trad. de Eni Orlandi. São Paulo: Pontes, 2015.

PLATÃO. Fedro. Trad. de Edson Bini. São Paulo: Edipro, 2012.

TESICH, S. A government of lies (political ethics). The Nation, Nova Iorque, n. 254, p. 12-13, 1992.

YUHAS, A. How does Donald Trump lie? A fact checker's final guide. The Guardian, 7 nov. 2016. Disponível em: https://www.theguardian.com/us-news/2016/nov/07/how-does-donald-trump-lie-factchecker. Acesso em: 5 set. 2017.

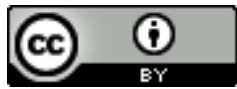

Este texto está licenciado com uma Licença Creative Commons Atribuição 4.0 Internacional. 